\title{
Modeling the frictional torque of a dry-lubricated tapered roller bearing considering the roller skewing
}

\author{
Chi ZHANG, Le GU*, Yuze MAO, Liqin WANG \\ Research Lab of Space \& Aerospace Tribology, Harbin Institute of Technology, Harbin 150001, China \\ Received: 05 April 2018 / Revised: 21 June 2018 / Accepted: 14 July 2018 \\ (C) The author(s) 2018. This article is published with open access at Springerlink.com
}

\begin{abstract}
In this paper, an equation for the calculation of the frictional torque of a dry-lubricated tapered roller bearing (TRB) is provided in which the effect of the roller skewing is emphasized. Calculations were performed to investigate the effect of the roller skewing on the torque of dry-lubricated TRB for two representative preload methods, that is, axial force preload and axial displacement preload. The results show that a proper roller skewing angle under axial force preload benefits the reduction of the TRB torque. However, the roller skewing angle should not exceed a certain critical value; otherwise, it will cause a steep rise in the TRB torque. Finally, the critical value of the roller skewing angle as a function of the friction coefficient and cage pocket clearance is presented. The developed torque model provides a tool for the internal design and torque optimization of dry-lubricated TRBs.
\end{abstract}

Keywords: tapered roller bearing; frictional torque; roller skewing; dry lubrication

\section{Introduction}

The use of dry-lubricated roller bearings has enormously increased during the past two decades in the aerospace industry, in particular for extreme temperature conditions [1-3]. It is of importance to study the frictional torque of a bearing with respect to the design because the bearing torque is not only related to the power loss but also the characteristic controlling a rotator system $[4,5]$. The frictional torque of a dry-lubricated tapered roller bearing (TRB) is significantly different from that of an oil-lubricated one because the friction coefficients of aerospace drylubricated TRBs are always much larger [6]. Although many studies have been conducted to study the friction torque of dry-lubricated ball bearings [7-9], few studies focused on the frictional torque of a dry-lubricated TRB.

The rollers in a TRB likely generate some degree of skewing during the operation due to the sliding friction at the rib-roller end contact. Many researchers investigated the roller skewing angle of oil-lubricated TRBs [10, 11]. Nelias et al. [12] proposed that the main parameter governing the roller skewing angle is the friction coefficient between the rib flange and roller end. Gupta et al. [13] studied the effect of the roller skewing on the dynamics of a TRB. It was found that the contact forces between the rollers and cage pockets and the stability of the cage are highly related to the roller skewing. However, the authors did not study how the roller skewing affects the frictional torque of a TRB. Because the friction coefficients under drylubricated conditions might be dozens of times higher than those under oil-lubricated conditions, the roller skewing angle would be large and the effect of the roller skewing on the bearing torque would be significant for a dry-lubricated TRB.

Many models were proposed for the running torque of a TRB [14-18]. Witte et al. [14] proposed a semiempirical equation to predict the running torque of

* Corresponding author: Le GU, E-mail: gule@hit.edu.cn 
TRBs under combined axial and radial loads. Aihara et al. [15] developed a running torque equation for the TRB based on the summation of the EHL (ElastoHydrodynamic Lubrication) rolling resistance of roller-race contacts, sliding friction in rib-roller end contacts, and internal friction of lubrication films. Aihara's model was later improved by Zhou and Hoeprich [16] to reduce calculation efforts. Creju et al. [17] introduced a dynamics model to study the effect of the EHL film thickness on the friction loss at rib-roller end contacts. Tong et al. [18] combined the TRB torque model developed by Aihara with the static TRB model with inner ring misalignment developed by themselves to study the effect of the inner ring misalignment on the torque of oil-lubricated TRBs. However, few of these torque models are associated with roller skewing.

The present study aims to predict the running torque of a dry-lubricated TRB by improving the existing TRB torque equation by considering the effect of roller skewing. The effects of roller skewing on the roller contact characteristics, such as roller-races contact load, roller-cage contact load, and contact pressure distributions, are analyzed and compared with the literature results. Then, a modified torque model based on the contact characteristics of the skewed rollers is proposed. The calculation of a TRB torque is performed with respect to the friction coefficient, clearance between roller and cage, and bearing preload method. Finally, the critical roller skewing angle for TRB torque optimization as a function of the friction coefficient and cage pocket clearance is given.

\section{The model}

\subsection{TRB equilibrium considering roller skewing}

To calculate the TRB torque considering the roller skewing, the contact forces between a skewed roller and the races should be determined in advance. This can be done by solving the static bearing equations relevant to the equilibrium of the skewed rollers and inner ring. The studied dry-lubricated TRB operates under ultra-low speed; hence, a static model of drylubricated TRB is considered.

Figure 1(a) shows the combination of radial and axial loads acting on a TRB. The load vector of the inner ring is $\{F\}^{\mathrm{T}}=\left\{F_{x}, 0, F_{z}\right\}$. The corresponding inner ring displacement vector is $\{\gamma\}^{\mathrm{T}}=\left\{\gamma_{x}, 0, \gamma_{z}\right\}$, considering a roller $g$ at the azimuthal angle of $\psi_{\mathrm{g}}$ (Fig. 1(b)). The contact loads $Q_{\mathrm{i}}, Q_{\mathrm{o}}$, and $Q_{\mathrm{f}}$ are generated owing to the interference between the races and roller. The subscripts $\mathrm{i}, \mathrm{o}$, and $\mathrm{f}$ represent the roller-inner raceway contact, roller-outer raceway contact, and roller endflange contact. The tangential friction force $F_{\mathrm{f}}$ increases due to sliding in the presence of a roller end-flange contact load $Q_{f}$. Hence, the roller carries out the composed motion of a translation vector, $\{u\}^{\mathrm{T}}=\left\{u_{x}, 0, u_{z}\right\}$, and a rotation vector, $\{\phi\}^{\mathrm{T}}=\left\{0, \phi_{y}, \phi_{z}\right\}$, as illustrated in Fig. 1(c).

The contact loads $Q_{\mathrm{i}}$ and $Q_{\mathrm{o}}$ can be calculated using the Palmgren's line contact equation and the slicing method. In the slicing method, the total contact length is cut into $N_{\mathrm{s}}$ slices. The total contact load $Q_{\mathrm{k}}, \mathrm{k}=\mathrm{i}$, o, is the summation of the individual contact force $q_{\mathrm{k}}$ on
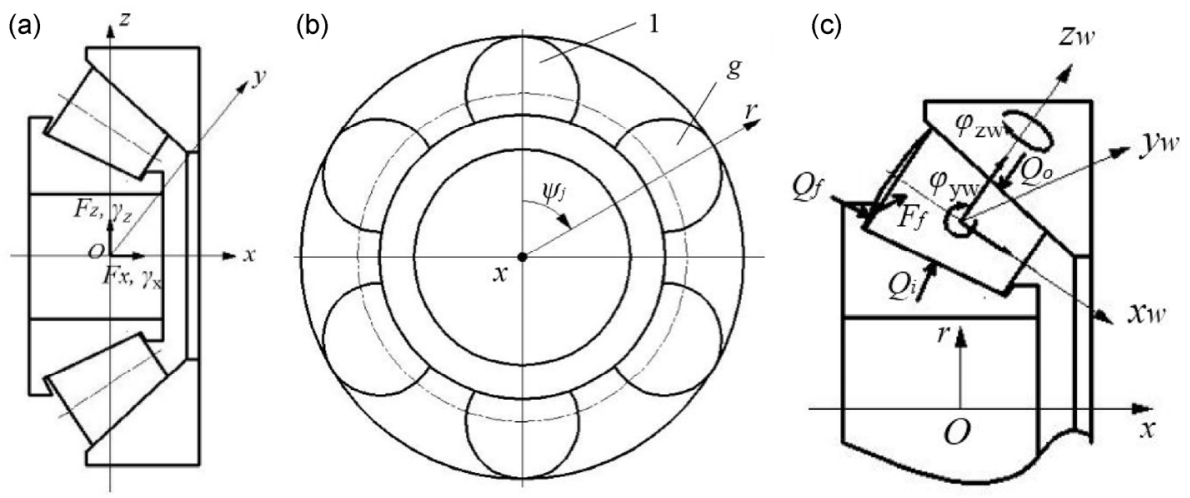

Fig. 1 Loads and displacements in a (a) fixed coordinate system $(x, y, z)$, (b) azimuthal coordinate system ( $x$, $r$, $\psi)$, and (c) roller coordinate system $\left(x_{w}, y_{w}, z_{w}\right)$. 
each slice and can be expressed as [19]:

$$
Q_{\mathrm{kg}}=\sum_{j=1}^{N_{\mathrm{s}}} q_{\mathrm{kgj}}=\sum_{j=1}^{N_{\mathrm{s}}} K_{l}\left(\delta_{\mathrm{kgj}}\right)^{10 / 9} \Delta l, k=i, o,
$$

where $Q_{\mathrm{kg}}$ is the total contact load between the roller $g$ and the races, $q_{\mathrm{kgj}}$ is the contact load on slice $j$ in roller $g, \Delta l$ is the length of one slice, $N_{\mathrm{s}}$ is the total number of slices on one roller, $N_{\mathrm{s}}=l_{\mathrm{w}} / \Delta l, K_{\mathrm{l}}$ is the loaddeflection constant for line contact, $K_{1}=8.06 \times 10^{4}(\Delta l)^{8 / 9}$ is the load-deflection constant for steel roller and races, $\delta_{\mathrm{kgj}}$ is the roller-race deflection on slice $j$ in roller $g$. This roller-race deflection $\delta_{\mathrm{kgj}}$ can be defined as follows:

$\delta_{k g j}\left(\{\gamma\}^{T},\{u\}^{T}, \varphi_{y}, \varphi_{z}\right)=\Delta_{k g j}\left(\{\gamma\}^{T},\{u\}^{T}\right)+\zeta_{k g j}\left(\varphi_{y}\right)+\eta_{k g j}\left(\varphi_{z}\right)$,

where $\Delta_{\mathrm{kgj}}$ is the deflection caused by translational movement, $\zeta_{\mathrm{kgj}}$ is the deflection caused by roller titling, and $\eta_{\mathrm{kg} j}$ is the deflection caused by roller skewing as a function of $\phi_{z}$. Creju provided explicit equations for $\Delta_{\mathrm{kgj}}$ and $\zeta_{\mathrm{kg}}$ [17]. In the present study, explicit equations for $\eta_{\mathrm{kgj}}$ in terms of the roller skewing angle $\phi_{z}$ and geometric parameters of the TRB are used (see below). As illustrated in Fig. 2(a), the slice 1 is located at the larger roller end; $D_{1}$ is the diameter of the larger roller end; $R_{1}$ is the pitch radius of the larger roller end; $\alpha_{\mathrm{i}}, \alpha_{\mathrm{o}}, \alpha_{\mathrm{r}}$ are the semi-cone angles of the inner race, outer race, and roller with respect to the bearing axis, respectively; $D_{\mathrm{j}}$ is the diameter of slice $\mathrm{j}$; and $R_{\mathrm{j}}$ is the pitch radius of slice $j$. Taking the cross-section passing through slice $\mathrm{j}$ (Fig. 2(a)) into account, a rigid displacement $\xi_{\mathrm{jyw}}$ in the $y_{w}$ direction is generated in this slice due to roller skewing, as illustrated in Fig. 2(b).
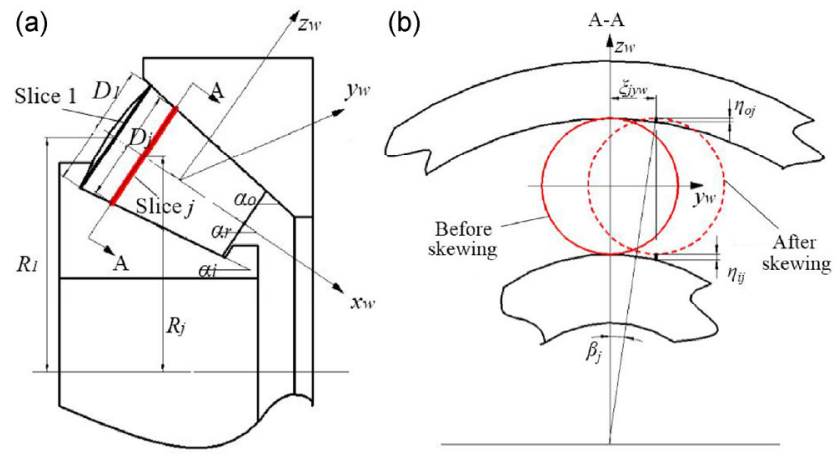

Fig. 2 Schematic showing the contact between a skewed slice and the races: (a) side view, (b) cross-sectional view.
The displacement $\xi_{\text {jyw }}$ of the outer race-slice contact point after roller skewing in Fig. 2(b) is

$$
\xi_{j y w}=\left[j-\left(N_{s}+1\right) / 2\right] \Delta l \varphi_{z}
$$

An angle shift $\beta_{\mathrm{j}}$ develops at the outer race-slice contact point due to the rigid displacement $\xi_{\mathrm{jyw}}$ and can be described as

$$
\begin{aligned}
\beta_{j} & \approx \tan \beta_{j}=\frac{\xi_{j y w}}{\left(R_{j} / \cos \alpha_{r}+D_{j} / 2\right)} \\
& =\frac{\Delta l}{\left(R_{j} / \cos \alpha_{r}+D_{j} / 2\right)}\left[j-\left(N_{s}+1\right) / 2\right] \varphi_{z}
\end{aligned}
$$

Harris [20] studied the contact interference between the skewed roller and races for cylindrical roller bearings. He suggested that the contact interference $\eta_{\mathrm{kj}}$ is the distance between initial slice-races contact points and final contact points in the $z_{w}$ direction. Thus, we obtain

$$
\begin{aligned}
& \eta_{o j}=\frac{\left[\left(N_{s} / 2-\left|j-\left(N_{s}+1\right) / 2\right|\right) \Delta l \varphi_{z}\right]^{2}}{\left(R_{j} / \cos \alpha_{r}+D_{j} / 2\right)} \cos \left(\alpha_{o}-\alpha_{r}\right) \\
& \eta_{i j}=\frac{\left(\left|j-\left(N_{s}+1\right) / 2\right| \Delta l \varphi_{z}\right)^{2}}{\left(R_{j} / \cos \alpha_{r}+D_{j} / 2\right)} \cos \left(\alpha_{r}-\alpha_{i}\right)
\end{aligned}
$$

As shown in Fig. 3, the roller skewing angle $\phi_{z}$ may be limited by the cage pocket clearance $\varepsilon_{c}$. The maximum skewing angle permitted by the cage pocket clearance is $\varepsilon_{\mathrm{d}} /\left(l_{w} / 2\right)$. If the skewing angles $\phi_{z}$ exceed $\varepsilon_{\mathrm{c}} /\left(l_{w} / 2\right)$, the actual skewing angles $\phi_{z}$ are limited to $\varepsilon_{\mathrm{c}} /\left(l_{w} / 2\right)$. A contact force between the skewed roller and cage pocket, $F_{c}$ is generated, as shown in Fig. 3.

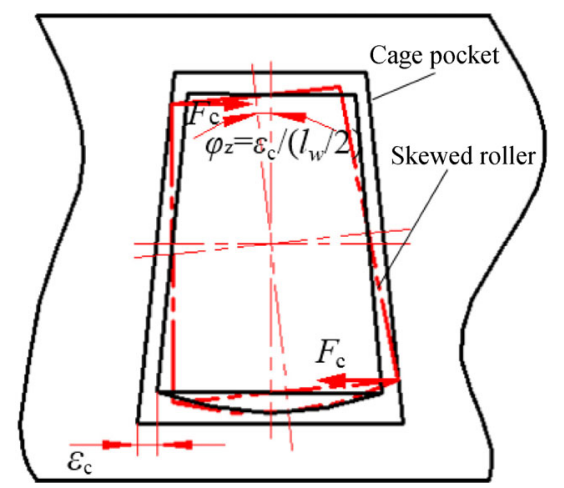

Fig. 3 Maximum roller skewing angle permitted by the clearance between roller and cage pocket. 
Therefore, the boundary conditions for skewing angles $\phi_{z}$ and cage contact force $F_{\mathrm{c}}$ can be expressed as

$$
\varphi_{z}<\varepsilon_{c} /\left(l_{w} / 2\right), F_{c}=0 \text { or } F_{c}>0, \varphi_{z}=\varepsilon_{c} /\left(l_{w} / 2\right)
$$

The force acting on a skewed roller is shown in Fig. 4. Owing to the angle shift $\beta_{j}$, the contact force $q_{\mathrm{kgj}}$ generates a tangential component $q_{\mathrm{kgiyw}}$ in the $y_{w}$ direction, which restores the roller rotation axis to its position parallel to the bearing axis, as shown in Fig. 4(a). In addition, if contact forces between the skewed roller and cage pocket $F_{\mathrm{c}}$ are generated, the forces resist the roller skewing. Figure 4(b) shows that the motion of the skewed roller induces a thrust force $F_{\text {kgt }}$ along the roller-races contact line. The thrust force $F_{\mathrm{kgjt}}$ acting on slice $\mathrm{j}$ in roller $g$ can be given by

$$
F_{\mathrm{kgjt}}=\mu q_{\mathrm{kgj}} \sin \left(c_{k} \varphi_{z}\right) ; k=i, o ; c_{i}=-1, c_{o}=1
$$

where $\mu$ is the friction coefficient. In Fig. $4, h$ is height of the roller end-flange contact point to the inner race, $R_{\mathrm{f}}$ is the distance between the roller gravity center and the roller end-flange contact force $Q_{\mathrm{f}}$, and $\varepsilon$ is the halftapered roller angle with respect to its own axis.

The force equilibria along the $x_{w}$-axis and $z_{w}$-axis are given by Eq. (8a) and Eq. (8b). The moment equilibrium in the $x_{w} o_{w} z_{w}$ plane relevant to roller titling is given by Eq. (8c). The moment equilibrium in the $y_{w} o_{w} z_{w}$ plane relevant to roller skewing is given by Eq. (8d).

$$
\sum_{j=1}^{N_{s}}\left(q_{o j}+q_{i j}\right) \cos \beta_{j} \sin \varepsilon+\sum_{j=1}^{N_{s}}\left(F_{o j t}-F_{i j t}\right) \cos \varepsilon-Q_{f} \cos \alpha_{f}=0
$$

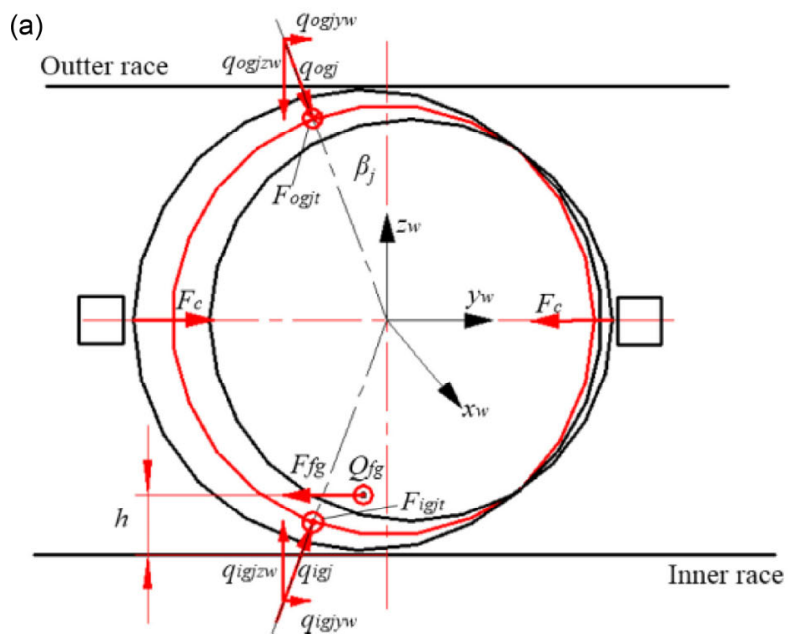

Fig. 4 Forces acting on a skewed roller in (a) $y_{\mathrm{w}} z_{w}$ view, (b) $x_{\mathrm{w}} z_{w}$ view.

$$
\sum_{j=1}^{N_{s}}\left(q_{o j}-q_{i j}\right) \cos \beta_{j} \cos \varepsilon+\sum_{j=1}^{N_{s}}\left(F_{o j t}-F_{i j t}\right) \sin \varepsilon-Q_{f} \sin \alpha_{f}=0
$$

$$
\begin{gathered}
\Delta l \sum_{j=1}^{N_{s}}\left(q_{o j}-q_{i j}\right) \cos \beta_{j}\left[j-\left(N_{s}+1\right) / 2\right]+ \\
\sum_{j=1}^{N_{s}}\left(F_{o j t}+F_{i j t}\right) \sin \varepsilon\left(D_{w} / 2\right)-Q_{f} R_{f}=0 \\
\frac{1}{2} l_{w} \mu Q_{f}-F_{c} l_{w}- \\
\frac{(\Delta l)^{2} \varphi_{z}}{\left(R_{j} / \cos \alpha_{r}+D_{j} / 2\right)} \sum_{j=1}^{N_{s}}\left(q_{o j}+q_{i j}\right)\left[j-\left(N_{s}+1\right) / 2\right]^{2}=0
\end{gathered}
$$

The equilibria of the inner ring are given by Eq. (9a) and Eq. (9b).

$$
\begin{aligned}
& F_{z}-\sum_{g=1}^{z} \cos \psi_{g}\left[\sum_{j=1}^{N_{s}}\left(q_{i g j} \cos \beta_{j} \cos \alpha_{i}+F_{i g j t} \sin \alpha_{i}\right)-Q_{f g} \cos \alpha_{f}\right]=0 \\
& F_{x}-\sum_{g=1}^{z}\left[\sum_{j=1}^{N_{s}}\left(q_{i g j} \cos \beta_{j} \sin \alpha_{i}+F_{i g j t} \cos \alpha_{i}\right)-Q_{f g} \cos \alpha_{f}\right]=0
\end{aligned}
$$

There are four unknowns, $u_{x}, u_{y}, \phi_{y}$, and $\phi_{z} / F_{c}$ for each roller in Eqs. (8a-8d). There are two unknowns $\gamma_{x}$ and $\gamma_{z}$ for the inner ring in Eqs. (9a-9b). Therefore, the static equations of a TRB considering roller skewing can be given by a set of $4 Z+2$ nonlinear equations with $4 Z+2$ unknowns. The iterative Newton-Raphson method was adopted to calculate the load and contact pressure distribution on each skewed roller.

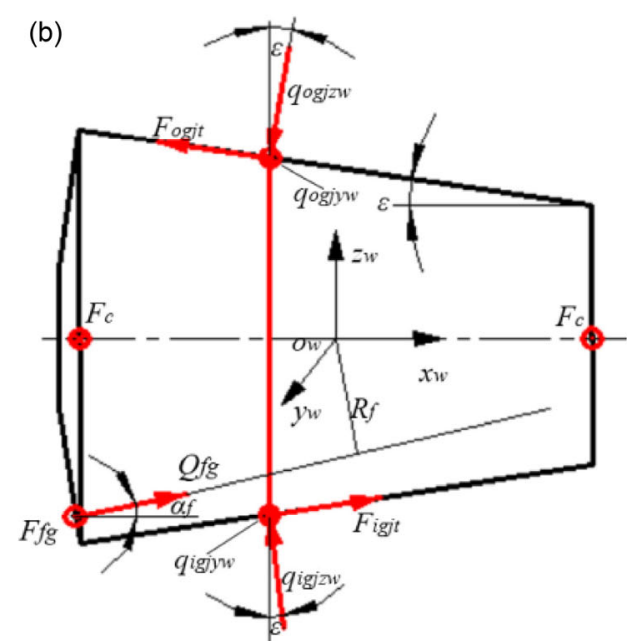




\subsection{TRB torque}

Most of the analytical equations developed to estimate the bearing torque are based on the law of energy conservation. The frictional torque of a TRB can be presented in terms of dividing the total frictional power loss within the bearing by the rotational speed of the inner ring:

$$
\begin{aligned}
& T_{\text {TRB }}=H_{\text {TRB }} / \omega, H_{\text {TRB }}=H_{\text {roller-race }}+H_{\text {end-rib }}+H_{\text {roller-cage }} \\
& T_{\text {roller-race }}=H_{\text {roller-race }} / \omega \\
& T_{\text {end-rib }}=H_{\text {end }} / \omega \\
& T_{\text {roller-cage }}=H_{\text {roller-cage }} / \omega
\end{aligned},
$$

where $T_{\mathrm{TRB}}$ is the friction torque of a TRB, $H_{\mathrm{TRB}}$ is the total friction power loss within a TRB, and $\omega$ is the rotational speed of the inner ring. The total power loss, $H_{\mathrm{TRB}}$, is the sum of the frictional power loss of the contact pair; $H_{\text {roller-race, }} H_{\text {end-rib, }}$ and $H_{\text {roller-cage }}$ are the friction power losses at the roller-race contact, rib-roller end contact, and roller-cage contact, respectively; and $T_{\text {roller-race, }} T_{\text {end-ribr }}, T_{\text {roller-cage }}$ are the roller-race-contributed torque, rib-roller end-contributed torque, and roller-cage-contributed torque, respectively. Figure 5 illustrates the microslip on the interfaces between a slice $\mathrm{j}$ and the races.

According to Harris [21], the friction power loss of the roller-races line contact due to microslip can be expressed as

$$
\begin{aligned}
& H_{\text {roller-race }}=\sum_{g=1}^{Z} \sum_{t=1}^{N_{t}} \frac{2 b_{t} \Delta l}{3 N_{t}} \sum_{j=1}^{N_{s}} S \mu \frac{q_{k g j}}{2 \pi \Delta l b_{k g j}} v_{k g j} \\
& v_{k g j}=\left[R_{j} / \cos \alpha_{r}+c_{k}\left(D_{j} / 2+(2 / 3) \delta_{k g j}\right)\right]\left(\omega-\omega_{g}\right) \cos \alpha_{r}- \\
& \quad\left[D_{j} / 2-(1 / 3) \delta_{k g j}\right] \omega_{s} \\
& k=i, o ; c_{i}=-1, c_{o}=1
\end{aligned}
$$

where $b_{\mathrm{kgj}}$ is half of the contact width between slice $\mathrm{j}$ and the races. The contact width is cut into $N_{\mathrm{t}}$ strips; $b_{\mathrm{t}}$ is the width of a strip; $S$ is the Simpson integral coefficient; $v_{\mathrm{kg}}$ is the slip velocity at the center of the rollerrace contact area for slice $\mathrm{j}$ in roller $g$ due to contact interference $\delta_{\mathrm{kg} ;} \omega_{\mathrm{s}}$ is the rotational roller speed; $\omega_{\mathrm{g}}$ is the orbital roller speed around the bearing axis. The relationship between $\omega_{\mathrm{s},} \omega_{\mathrm{g}}$ and $\omega$ can be expressed as

$$
\begin{aligned}
& \omega_{s}=\omega \sin \alpha_{i} \sin \alpha_{o} /\left[\left(\sin \alpha_{i}+\sin \alpha_{o}\right) \sin \left(\alpha_{r}-\alpha_{i}\right)\right] \\
& \omega_{g}=\omega \sin \alpha_{i} /\left(\sin \alpha_{i}+\sin \alpha_{o}\right)
\end{aligned}
$$

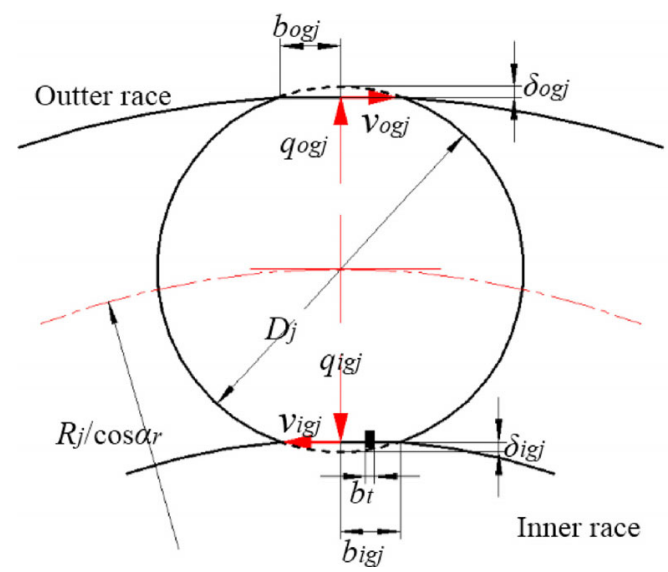

Fig. 5 Schematic showing the microslip of the roller-races contact.

The friction power loss of the roller end-rib flange contact due to sliding is illustrated in Fig. 6, where $R_{\mathrm{o}}$ is the mean radius of the outer race, $D_{\mathrm{o}}$ is the mean diameter of the roller, and $b_{\mathrm{f}}$ is the semi-width of the roller end-flange contact.

Karna [22] discussed the rib contribution to the bearing torque and presented an analytical equation for the estimation of the friction power loss $H_{\text {end-rib }}$ :

$$
H_{\text {end-rib }}=\omega \sum_{g=1}^{z} \mu Q_{f g} h \sqrt{1+0.18\left(\frac{b_{f g}}{h}\right)^{2}} \frac{R_{o}}{D_{o}}
$$

The friction power loss of the roller-cage contact can be expressed as

$$
H_{\text {roller-cage }}=\sum_{g=1}^{Z} \mu F_{c g} \omega_{s} D_{o}
$$

The calculation of a dry-lubricated TRB torque can

(a)

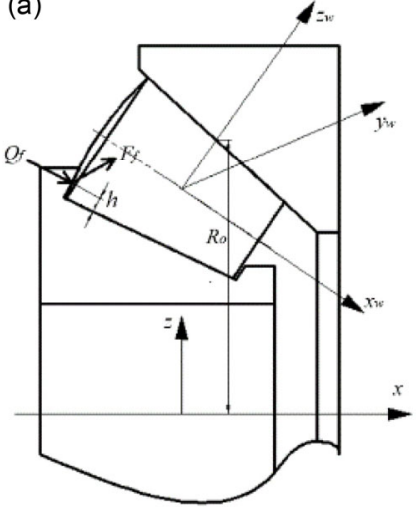

(b)

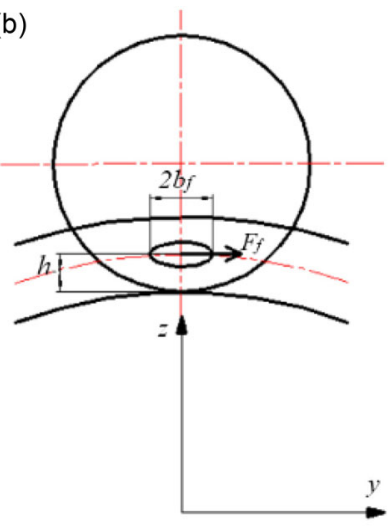

Fig. 6 Schematic showing the point contact between the roller end and rib flange. 
be performed based on the load distribution within a TRB considering the roller skewing. The steps to solve the numerical analysis for dry-lubricated TRB torque are presented in the appendix.

\section{Results and discussion}

The torque calculation was performed for 32018X TRB; the geometrical properties are listed in Table 1. Axial preload is always required for the TRB for the proper seating of the rollers in the races. In the present study, two representative axial preloading methods were considered: constant axial force preload and constant axial displacement preload. The effects of the roller skewing on the TRB torque under the two preload conditions were investigated. The operation speed of the dry-lubricated TRB is $60 \mathrm{rpm}$. Because the skewing of the rollers is mainly governed by the friction at the roller end-rib flange interface [13], the friction coefficients at the roller-races contacts, roller-cage contacts, and roller end-rib flange contacts are assumed to be identical.

Table 1 Structural parameters of tapered roller bearing $32018 \mathrm{X}$.

\begin{tabular}{cccc}
\hline Parameters & Value & Parameters & Value \\
\hline $\begin{array}{c}\text { Roller length } l_{w} / \mathrm{mm} \\
\text { Roller large end } \\
\text { diameter } D_{w} / \mathrm{mm}\end{array}$ & 20.96 & Cone race half angle $\alpha_{\mathrm{i}} /^{\circ}$ & 12.75 \\
$\begin{array}{c}\text { Radius of roller end } \\
\text { sphere } R_{\mathrm{s}} / \mathrm{mm}\end{array}$ & 244.14 & Roller half angle $\alpha_{\mathrm{r}} /{ }^{\circ}$ & 14.25 \\
$\begin{array}{c}\text { Roller number } Z \\
\text { Ren race half angle } \alpha_{\mathrm{o}} /{ }^{\circ}\end{array}$ & 15.75 \\
\hline
\end{tabular}
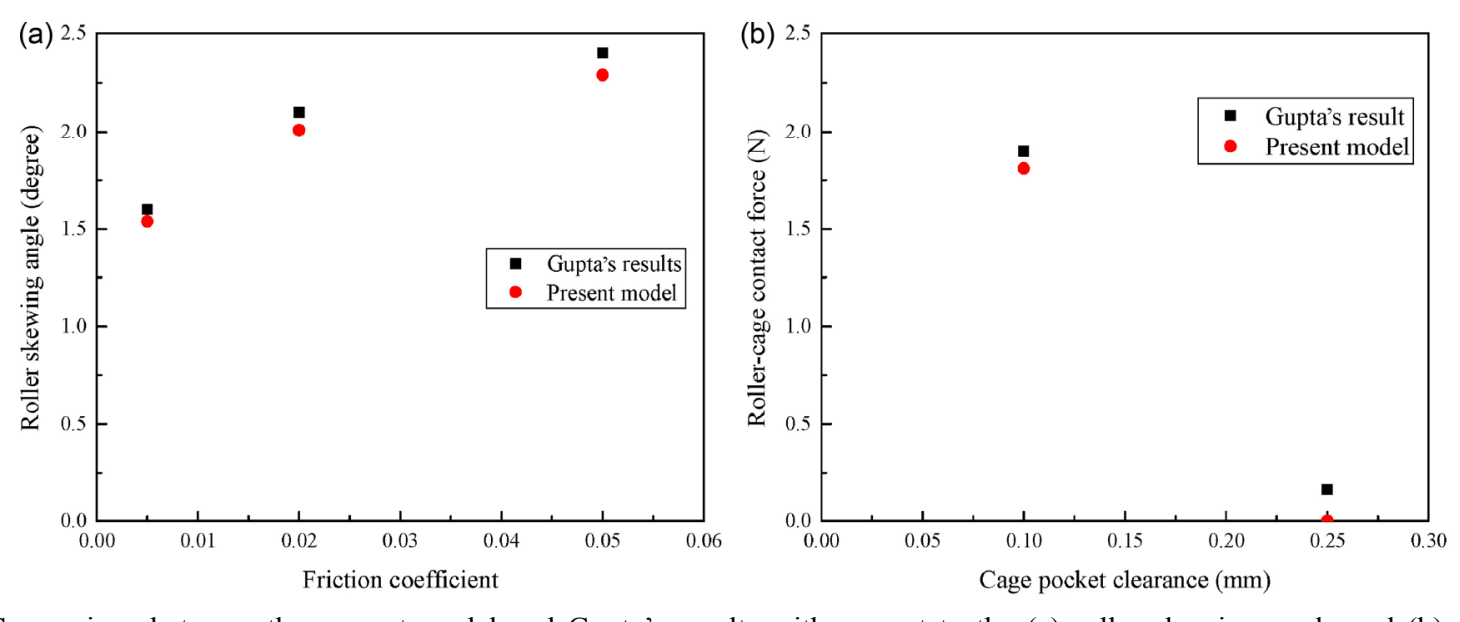

Fig. 7 Comparison between the present model and Gupta's results with respect to the (a) roller skewing angle and (b) roller-cage contact force. the dynamics of the cage in a tapered roller bearing. By adopting the same geometric TRB parameters and load conditions as reported in [13], the roller skewing angles at three friction coefficients of $0.005,0.02$, and 0.05 were compared (Fig. 7(a)).The comparisons of the roller-cage contact forces at cage pocket clearances of $0.1 \mathrm{~mm}$ and $0.25 \mathrm{~mm}$ are shown in Fig. 7(b). The comparisons show agreement between the results of the present calculation and that of Gupta, with a maximum difference below $4 \%$.

It is interesting that the roller skewing angle calculated with the present model is slightly smaller than that of Gupta. The roller-cage contact force calculated with the present model is also somewhat smaller than that of Gupta. In the present model, roller skewing causes the roller-races contact to be more concentrated at the roller ends, which subsequently results in the increase in restore moments provided by the rollerrace contact, as depicted in Eq. (5). However, the effect of the roller skewing on the roller-races contact is neglected in Gupta's results. Hence, the restore moments, which resist the roller skewing, calculated with the present model are larger than that calculated with Gupta's model. Thus, the roller skewing angle calculated with the present model is slightly smaller than that of Gupta. For a small skewing angle, the effect of the roller skewing on the roller-cage contact force is less significant, as proven by the comparisons shown in Fig. 7(b). However, with the increase in the roller 
skewing angle, the skewing of the roller has a notable effect on the contact characteristics of the roller, which subsequently affects the torque of a TRB.

\subsection{Effect of the friction coefficient on the TRB torque}

Figure 8 illustrates the effect of the friction coefficient on the torque of the TRB with an axial displacement preload of $0.01 \mathrm{~mm}$ and radial load of $35000 \mathrm{~N}$. The clearance between the roller and cage pocket is $0.9 \mathrm{~mm}$.

The increase rate of the $T_{\mathrm{TRB}}$ significantly changes when the friction coefficient is above 0.25 . The change in the $T_{\text {TRB }}$ increase rate can be attributed to the quadratic increase in $T_{\text {roller-cage }}$ with the friction coefficient.

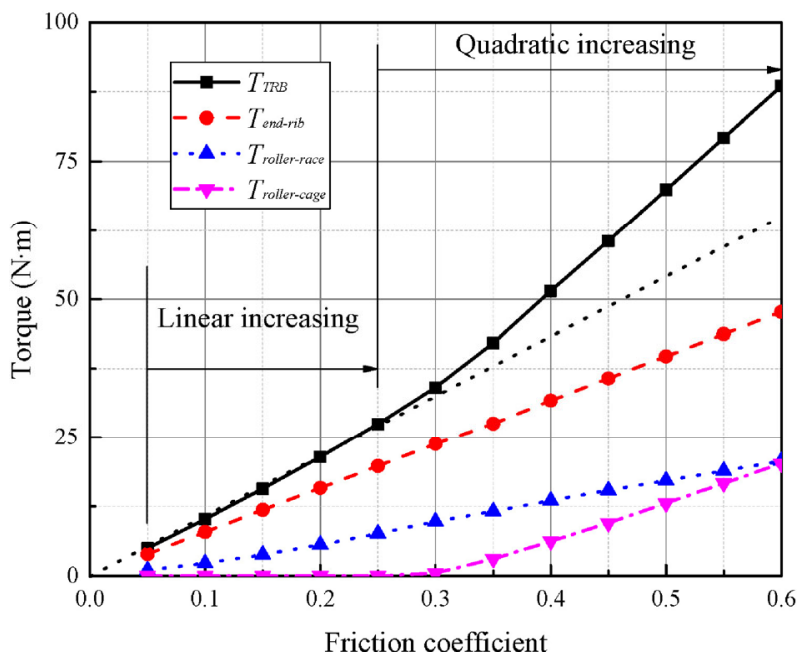

Fig. 8 Effect of friction coefficient on the torque of TRB with axial displacement preloading.

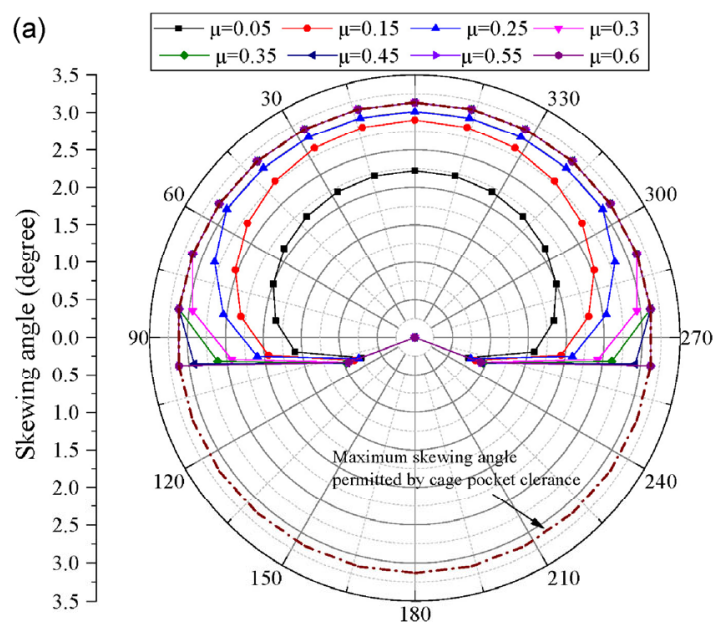

Figure 8 shows that $T_{\text {end-rib }}$ and $T_{\text {roller-race }}$ always linearly increase with the friction coefficient. However, $T_{\text {roller-cage }}$ shows a quadratic growth with respect to the friction coefficient when the friction coefficient is above 0.25 ; $T_{\text {roller-cage }}$ is even larger than $T_{\text {roller-race }}$ when the friction coefficient reaches 0.6.

The quadratic growth of $T_{\text {roller-cage }}$ is related to the roller skewing. Figure 9 illustrates the effect of the friction coefficient on the distribution of the roller-cage contact forces and roller skewing angle. The skewing angles of 11 rollers reach the maximum value permitted by the cage pocket clearance when the friction coefficient reaches 0.25, as shown in Fig. 9(a). Under this condition, roller-cage contact forces are generated to restore the roller skewing. However, it should be noted that the increase in the friction coefficient also leads to the nonlinear increment in the roller-cage contact force, as illustrated in Fig. 9(b). Hence, for skewed roller-cage pocket tribo-pairs, the increase in the friction coefficient results in the quadratic growth of the tangential friction force, which subsequently leads to the quadratic growth of $T_{\text {roller-cage, }}$ as shown in Fig. 8.

Regarding the stiffness of the 32018X TRB, a combination of axial force preload of $12,970 \mathrm{~N}$ and radial load of 35,000 N produces the same roller load distributions as those based on the combination of axial displacement preload of $0.01 \mathrm{~mm}$ and radial load of $35,000 \mathrm{~N}$ under static conditions. However, the TRB torque with axial force preloading differs from that with axial displacement preloading when the roller skewing is considered. Figure 10 illustrates the effect

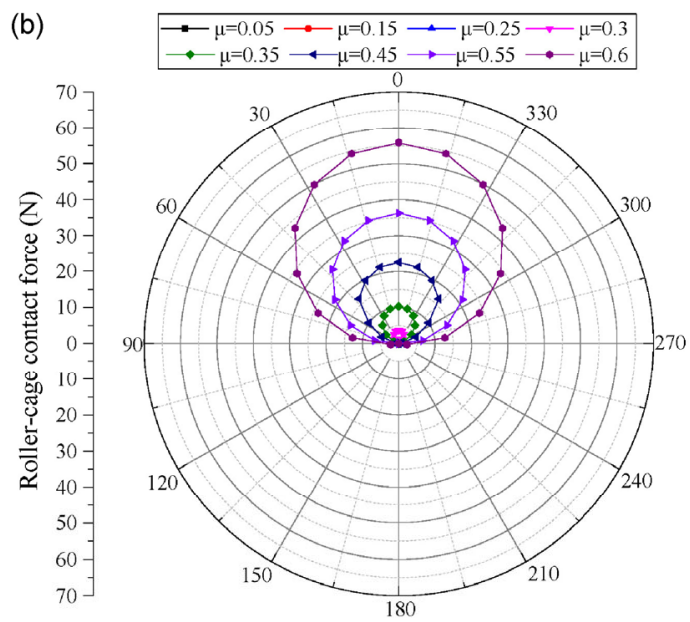

Fig. 9 Effect of friction on roller skewing angle and roller-cage contact force with axial bearing displacement preloading: (a) roller skewing angles, (b) roller-cage contact forces. 


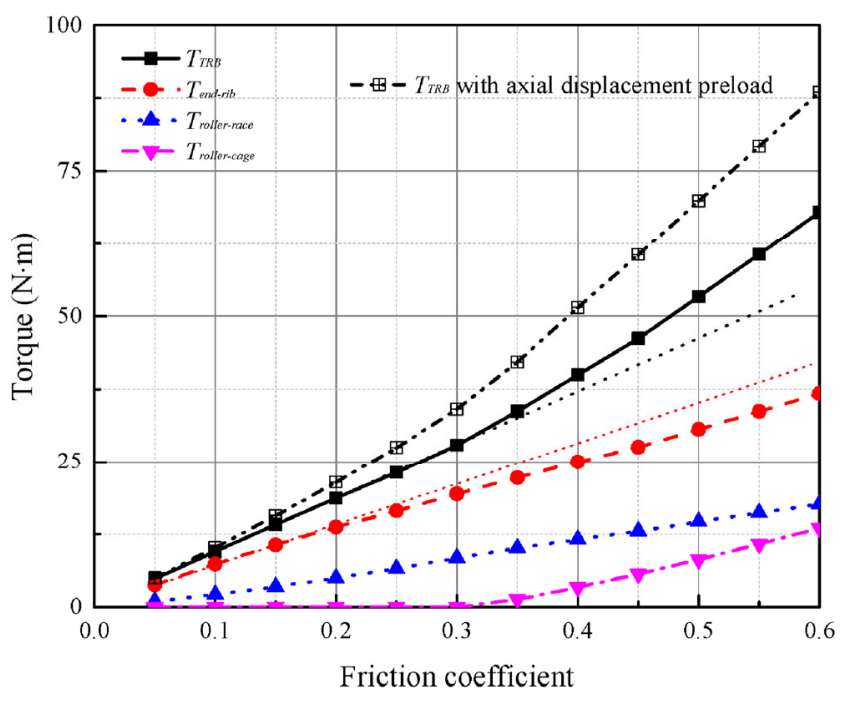

Fig. 10 Effect of the friction coefficient on the torque of the TRB with axial force preloading.

of the friction coefficient on the torque of the TRB with an axial force preload of $12,970 \mathrm{~N}$ and radial load of $35,000 \mathrm{~N}$. The clearance between the roller and cage pocket is also $0.9 \mathrm{~mm}$. For comparison, the $T_{\mathrm{TRB}}$ with axial displacement preload is also depicted.

In contrast to the $T_{\mathrm{TRB}}$ with axial displacement preload, the change in the increasing rate of $T_{\mathrm{TRB}}$ under axial force preload conditions occurs at a higher friction coefficient of 0.3. Meanwhile, the $T_{\mathrm{TRB}}$ and each torque component under axial force preload conditions are always lower than those under axial displacement preload conditions.

Figure 11 illustrates the effect of the friction coefficient on the distribution of the roller end-rib flange contact force and roller-outer race contact forces under axial force preload conditions. The parameters $Q_{\mathrm{f}}$ and $Q_{o}$ decrease with increasing friction coefficient. As indicated by Eq. (9b), the thrust force $F_{\mathrm{ijgt}}$ along the inner race partly offsets the axial load of the TRB. The magnitude of $F_{\mathrm{iggt}}$ is proportional to the value of the friction coefficient and skewing angle, as depicted by Eq. (7). With increasing friction coefficient, the thrust force $F_{\text {ijgt }}$ increases and a higher axial bearing load is offset. Hence, the contact forces $Q_{\mathrm{f}}$ and $Q_{\mathrm{o}}$ decrease with increasing friction coefficient under axial force preload conditions, as illustrated by Figs. 11(a) and 11(b). Moreover, owing to the reduction in the axial bearing load, the number of rollers in contact with the races also decreases (Fig. 11(a)). There are 13 rollers in contact with the races under axial force preload conditions compared with 15 rollers in contact with the races under axial displacement preload conditions. The reduction in the number of loaded rollers also benefits the reduction of the TRB torque.

\subsection{Effect of the cage pocket clearance on the TRB torque}

Figure 12 compares the effect of the cage pocket clearance on the TRB torque between an axial displacement preload of $0.01 \mathrm{~mm}$ and axial force preload of $12,970 \mathrm{~N}$. The radial load is $35,000 \mathrm{~N}$ for the two preload conditions. The friction coefficient is 0.5 .

As shown in Fig. $12(\mathrm{a})$, the bearing torques $T_{\text {TRB }}$ with different axial preload both decrease with increasing cage pocket clearance. With the increase in the cage pocket clearance from $0.3 \mathrm{~mm}$ to $1.8 \mathrm{~mm}, T_{\text {end-rib }}$ with axial displacement preload remains unchanged and
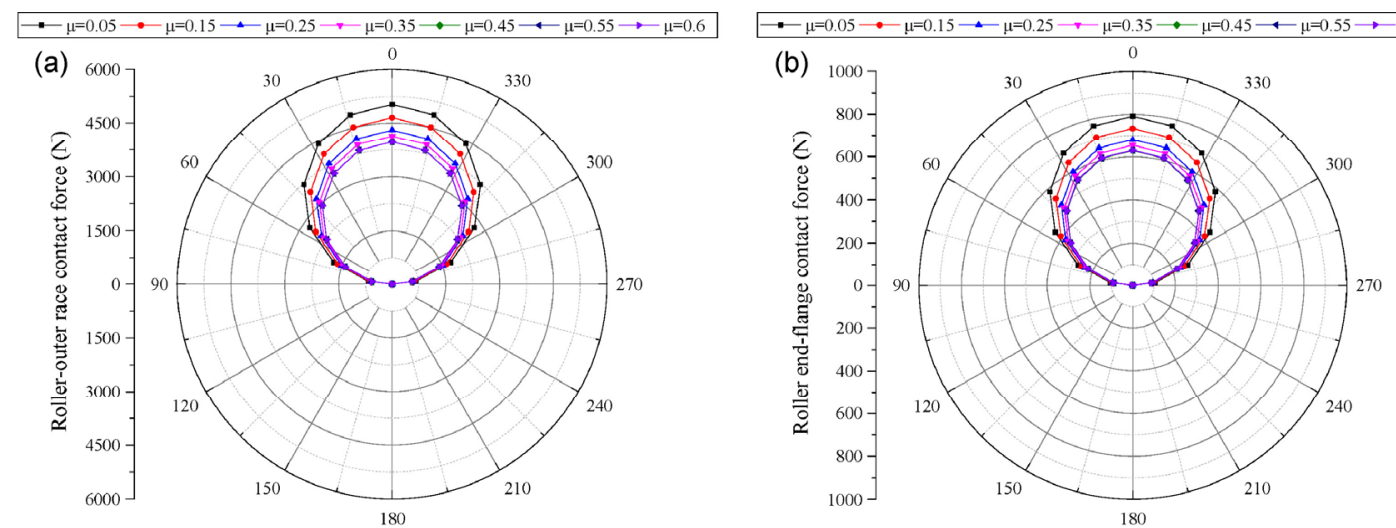

Fig. 11 Effect of the friction on the roller load distribution with axial bearing force preload: (a) roller-outer race contact force, (b) roller end-flange contact force. 
(a)

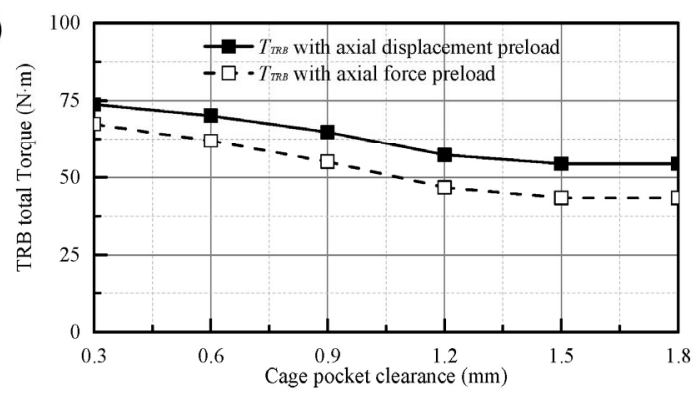

(c)

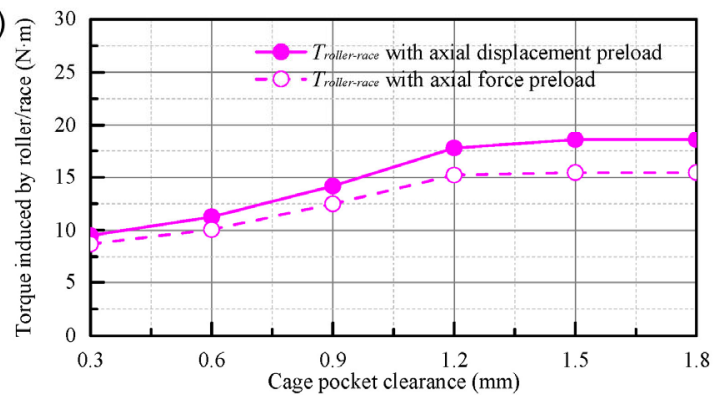

(b)

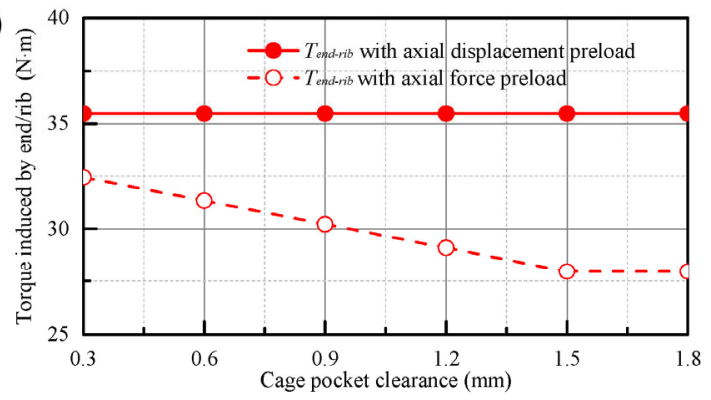

(d)

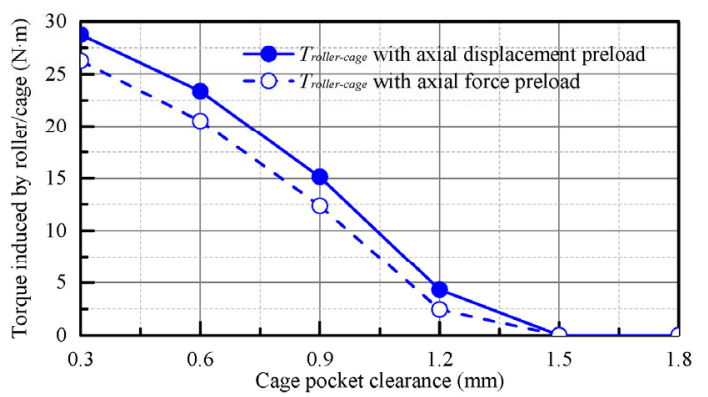

Fig. 12 Effect of the cage pocket clearance on the (a) total bearing torque, (b) roller end-rib-contributed torque, (c) roller-race-contributed torque, and (d) roller-cage-contributed torque.

$T_{\text {end-rib }}$ with axial force preload decreases by $4.4 \mathrm{~N} \cdot \mathrm{m}$, as shown in Fig. 12(b); $T_{\text {roller-cage }}$ with axial displacement preload decreases by $29.3 \mathrm{~N} \cdot \mathrm{m}$, and $T_{\text {roller-cage }}$ with axial force preload decreases by $26.5 \mathrm{~N} \cdot \mathrm{m}$, as shown in Fig. 12 (d). However, $T_{\text {roller-race }}$ with axial displacement preload increases by $7.5 \mathrm{~N} \cdot \mathrm{m}$ and $T_{\text {roller-race }}$ with axial force preload increases by $7.2 \mathrm{~N} \cdot \mathrm{m}$, as shown in Fig. 12(c).

The differences in the variation of each torque component depending on the cage pocket clearance are related to the changes in the roller contact characteristics resulting from the roller skewing. Figure 13 illustrates the effect of the cage pocket clearance on the roller skewing angle and roller-cage contact force under axial force preload conditions. The roller skewing angles increase and the roller-cage contact forces decrease with increasing cage pocket clearance. As depicted in Eq. (6) and Fig. 13(a), the actual skewing angle of the rollers increases with increasing cage pocket clearance. The contact force $q_{\mathrm{kgj}}$ generates a larger restore force $q_{\mathrm{kggyw}}$ under larger roller skewing angle, as depicted by Eq. (8d). Hence, with increasing cage pocket clearance, the roller-cage contact force, which also restores the skewing of the roller, reduces
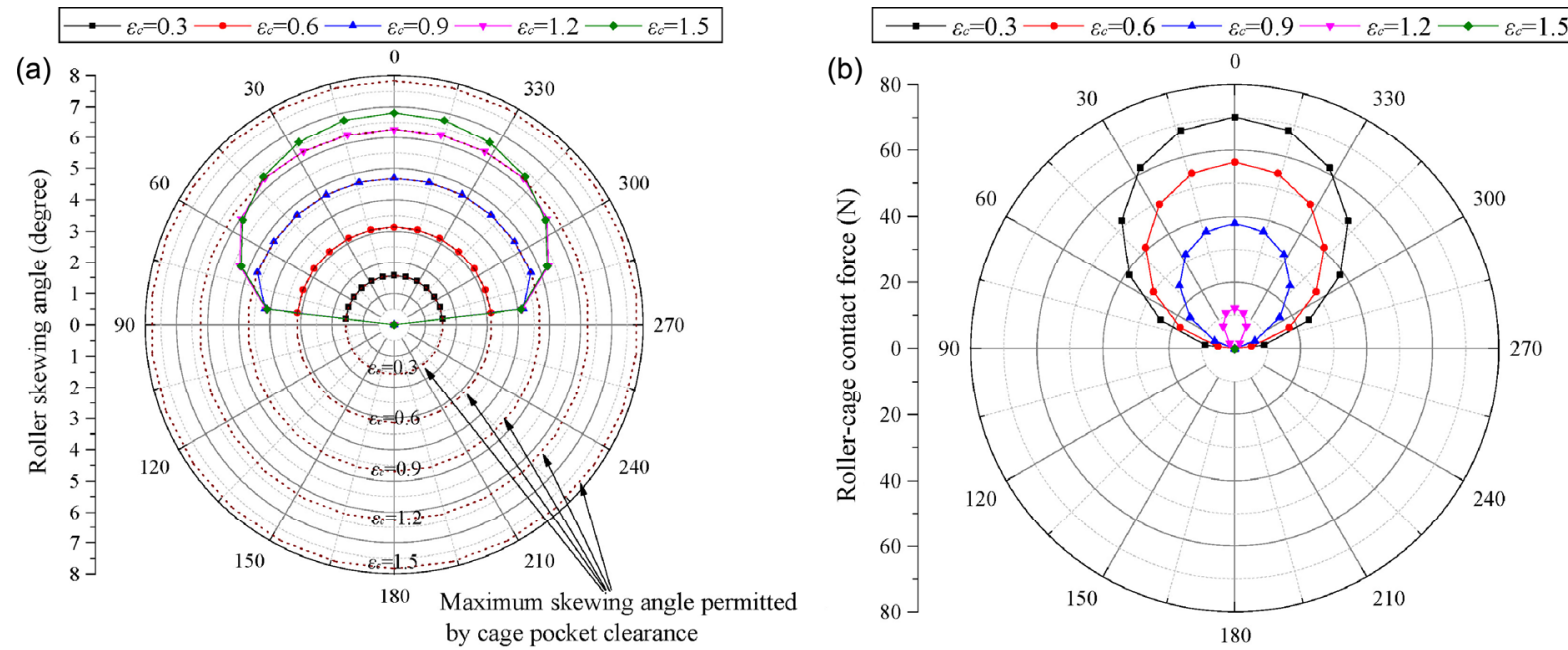

Fig. 13 Effect of the cage pocket clearance on the (a) roller skewing angles and (b) roller-cage contact force. 
(Fig. 13(b)). Note that the restore moments generated by the roller-races contact forces are sufficient to balance the skewing moment induced by the roller end-flange friction when the cage pocket clearance reaches $1.5 \mathrm{~mm}$. Hence, the actual skewing angle of each roller is lower than the maximum skewing angle permitted by the cage pocket clearance, as shown in Fig. 13(a). Under this condition, roller-cage contact forces are absent (Fig. 13(b)).

The total torque $T_{\text {TRB }}$ under axial force preload conditions is always lower than that under axial displacement preload conditions for different cage pocket clearances. As discussed in Section 3.2, the thrust force $F_{\text {ijgt }}$ along the inner race partly offsets the axial load of the TRB. Meanwhile, the magnitude of $F_{\mathrm{ijg}}$ is proportional to the value of the roller skewing angle, as depicted by Eq. (7). Hence, when the cage pocket clearance increases, the contact loads on the rollers decrease under axial force preload conditions (Fig. 14(b)). However, under axial displacement preload conditions, the contact loads on the rollers do not decrease (Fig. 14(a)).

As discussed above, the large cage pocket clearance results in a large roller skewing angle, which benefits the reduction of the roller contact load. However, it is interesting that $T_{\text {roller-race }}$ increases with increasing cage pocket clearance, as shown in Fig. 12(c). In general, the friction power loss depends on the friction force and relative sliding velocity. As depicted in Eq. (11), the microslip velocities on each slice along the roller are not equivalent owing to the tapered angle of the roller. The microslip velocity reaches the maximum value at the large roller end-races contact interfaces. Hence, when the contact loads are concentrated at the large roller end, the friction power loss between the roller and races increases. Taking roller 1 for example, Fig. 15 illustrates the effect of the cage pocket clearance on the contact pressure distribution along the roller. The location of the maximum contact pressure changes from the small end to the large end. When a large cage pocket clearance of $1.5 \mathrm{~mm}$ is applied, the contact pressure at the large roller end increases by $22 \%$ compared with the decrease (by $8.3 \%$ ) of the total contact load on this roller. The effect of the contact load concentration due to roller skewing is greater than that of the decreased contact load. As a result, $T_{\text {roller-race }}$ increases (Fig. 12(c)).

\subsection{TRB torque optimization regarding the friction coefficient and cage pocket clearance}

For a TRB with given structural parameters, $T_{\text {roller-cage }}$ is generated owing to the permitted skewing angle determined by the lower clearance between the roller and cage pocket compared with the roller skewing angle owing to the traction force at the roller end-flange contact. Hence, $T_{\text {roller-cage }}$ can be reduced or eliminated in two ways, that is, by increasing the permitted skewing angle corresponding to the cage pocket
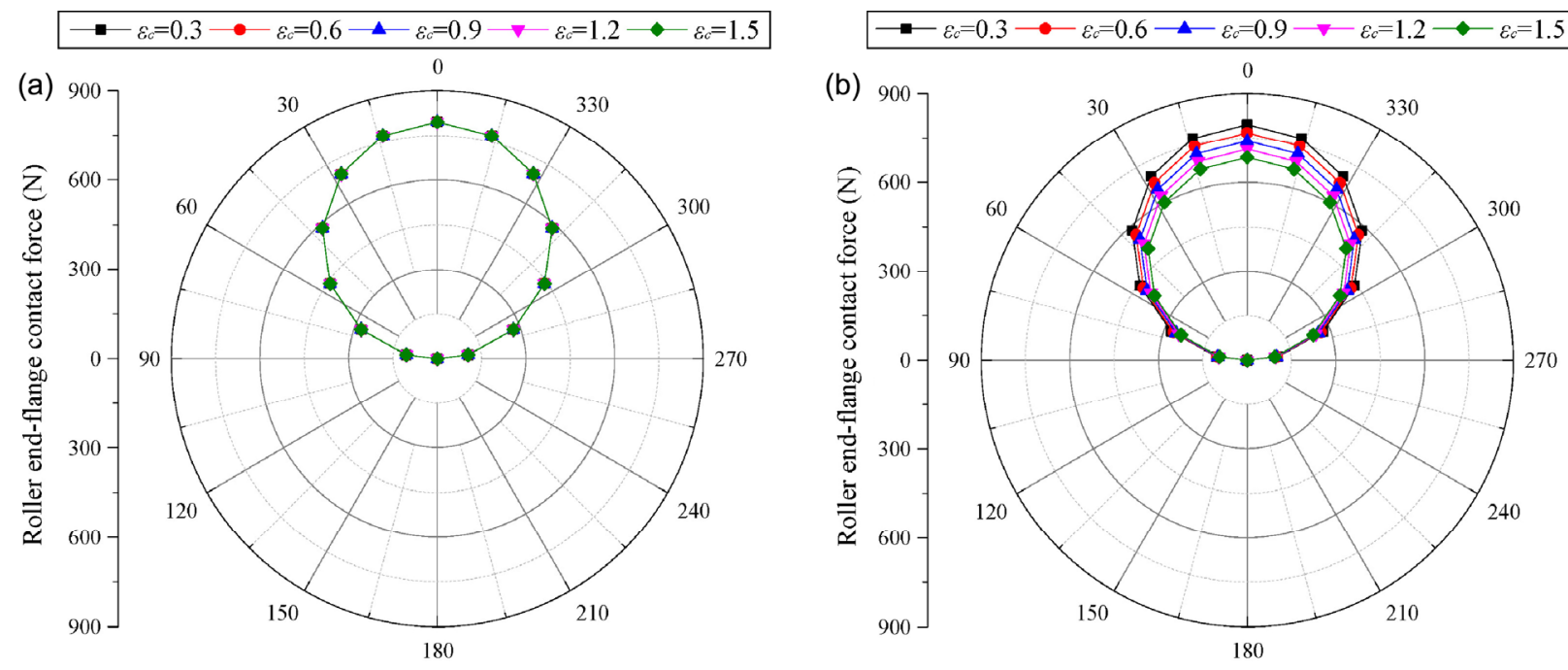

Fig. 14 Effect of the cage pocket clearance on the roller end-flange contact force under (a) axial displacement preload and (b) axial force preload. 


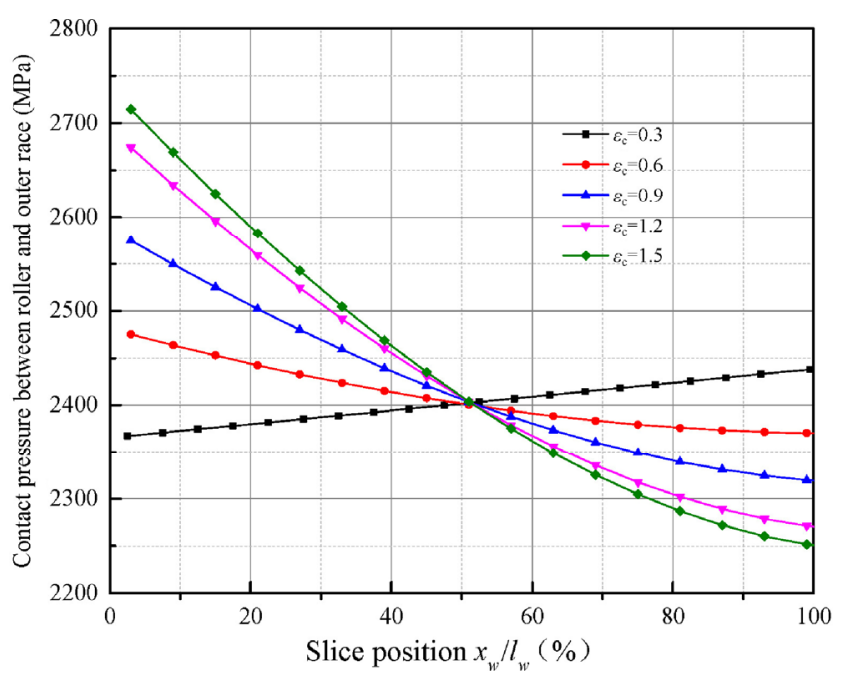

Fig. 15 Effect of the cage pocket clearance on the contact pressure distribution along the roller.

clearance increase or by reducing the intended roller skewing angle corresponding to the friction coefficient reduction, as demonstrated in Sections 3.2 and 3.3. By employing polynomial fitting, the minimum cage pocket clearance can be determined as a function of the friction coefficient to eliminate $T_{\text {roller-cage }}$ in $32018 \mathrm{X}$ TRB (Fig.16).

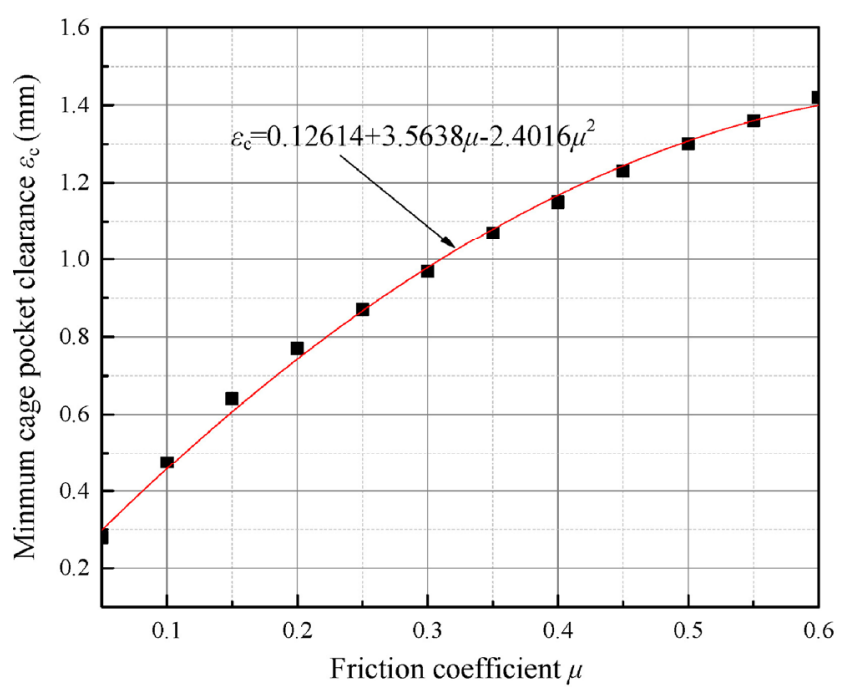

Fig. 16 Minimum cage pocket clearance as a function of the friction coefficient to eliminate the friction loss between the roller and cage pocket.

\section{Conclusions}

In the present study, the effects of the skewed rollerraces contact and skewed roller-cage pocket contact are investigated. The effect of the roller skewing angle on the roller load is studied for two representative preload methods: axial force preload and axial displacement preload. A torque equation coupled with the roller skewing effects is developed for a drylubricated TRB with a large roller skewing angle during operation.

1) Roller skewing alters the roller-races and rollercage pocket contact characteristics, which results in the subsequent change in the TRB torque.

2) The application to a $32018 X$ TRB shows that the roller skewing increases the TRB torque by $24 \%$ at a friction coefficient of 0.6 . Increasing the cage pocket clearance not only reduces the friction torque caused by the roller skewing but also the torque caused by the roller end-flange. However, the friction torque caused by the roller-races slightly increases with increasing cage pocket clearance.

3) A proper roller skewing angle with axial bearing force preloading benefits the reduction of the TRB torque because the race thrust force generated by the skewed roller partly offsets the axial load of the TRB.

4) A critical value of the roller skewing angle, which is a function of the friction coefficient, is proposed.

\section{Acknowledgments}

The authors are grateful for the support of the National Natural Science Foundation of China (Nos. 51675120 and U1637206).

Open Access: The articles published in this journal are distributed under the terms of the Creative Commons Attribution 4.0 International License (http://creativecommons.org/licenses/by/4.0/), which permits unrestricted use, distribution, and reproduction in any medium, provided you give appropriate credit to the original author(s) and the source, provide a link to the Creative Commons license, and indicate if changes were made.

\section{Appendix}

The steps to solve the numerical analysis for drylubricated TRB torque are presented in Fig. 17. 


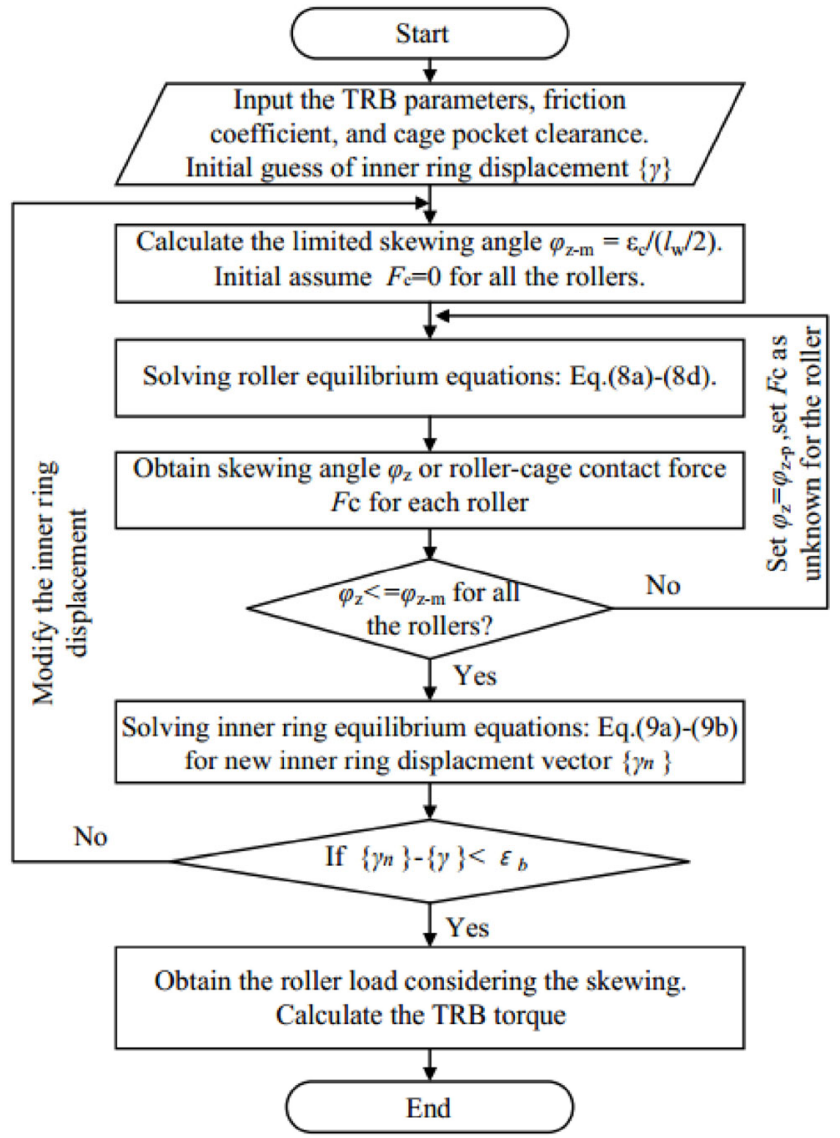

Fig. 17 Flow diagram for the numerical analysis.

\section{References}

[1] Obara S, Suzuki M. Long-term operation of $\mathrm{Si}_{3} \mathrm{~N}_{4}$ ball bearings at temperatures up to $650{ }^{\circ} \mathrm{C}$ in ultra-high vacuum. Tribol Trans 40(1): 31-40 (1997)

[2] Nishimura M, Suzuki M. Solid-lubricated ball bearings for use in a vacuum-state-of-the-art. Tribol Int 32(11): 637-647 (1999)

[3] Eiden M, Seiler R. Space mechanisms and tribology challenges of future space missions. Acta Astronaut 55(11): 935-943 (2004)

[4] Lostado R, García R E, Martinez R F. Optimization of operating conditions for a double-row tapered roller bearing. Int J Mech Mater Des 12(3): 353-373 (2016)

[5] Lostado R, Martinez R F, Mac Donald B J. Determination of the contact stresses in double-row tapered roller bearings using the finite element method, experimental analysis and analytical models. J Mech Sci Technol 29(11): 4645-4656 (2015)
[6] Miyoshi K. Considerations in vacuum tribology (adhesion, friction, wear, and solid lubrication in vacuum). Tribol Int 32(11): 605-616 (1999)

[7] Ohta H, Kanatsu M. Running torque of ball bearings with polymer lubricant (effect of the enclosure form of polymer lubricant). Tribol Trans 48(4): 484-491 (2005)

[8] Marquart M, Wahl M, Emrich S, Zhang G, Sauer B, Kopnarski M, Wetzel B. Enhancing the lifetime of $\mathrm{MoS}_{2}-$ lubricated ball bearings. Wear 303(1-2): 169-177 (2013)

[9] Gonçalves D, Pinho S, Graça B, Campos A V, Seabra J H O. Friction torque in thrust ball bearings lubricated with polymer greases of different thickener content. Tribol Int 96: 87-96 (2016)

[10] Yang Y, Danyluk S, Hoeprich M. Rolling element skew in tapered roller bearing. Tribol Trans 43(3): 564-568 (2000)

[11] Yang Y Y, Danyluk S, Hoeprich M. On the measurement of skew of tapered roller bearings. Tribol Lett 6(3-4): 221 (1999)

[12] Nelias D, Bercea I, Paleu V. Prediction of roller skewing in tapered roller bearings. Tribol Trans 51(2): 128-139 (2008)

[13] Gupta P K. On the dynamics of a tapered roller bearing. J Tribol 111(2): 278-287 (1989)

[14] Witte D C. Operating torque of tapered roller bearings. Tribol Trans 16(1): 61-67 (1973)

[15] Aihara S. A new running torque formula for tapered roller bearings under axial load. $J$ Tribol 109(3): 471-477 (1987)

[16] Zhou R S, Hoeprich M R. Torque of tapered roller bearings. J Tribol 113(3): 590-597 (1991)

[17] Creju S, Bercea I, Mitu N. A dynamic analysis of tapered roller bearing under fully flooded conditions Part 1: Theoretical formulation. Wear 188(1-2): 1-10 (1995)

[18] Tong V C, Hong S W. The effect of angular misalignment on the running torques of tapered roller bearings. Tribol Int 95: 76-85 (2016)

[19] Palmgren A. Ball and Roller Bearing Engineering. 3rd ed. Philadelphia (USA): SKF Industries Inc., 1959.

[20] Harris T A, Kotzalas M N, Yu W K. On the causes and effects of roller skewing in cylindrical roller bearings. Tribol Trans 41(4): 572-578 (1998)

[21] Harris T A. Rolling Bearing Analysis. New York (USA): John Wiley \& Sons, 2001: 275.

[22] Karna C L. Performance characteristics at the rib roller end contact in tapered roller bearings. Tribol Trans 17(1): 14-21 (1974) 


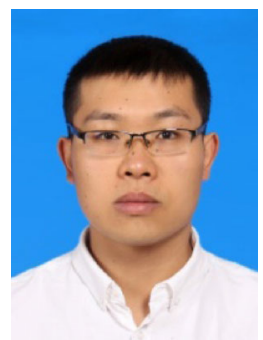

Chi ZHANG. He received his M.S degree in mechanical engineering in 2013 from Harbin Institute of Technology, Harbin, China. After then, he was a Ph.D student in

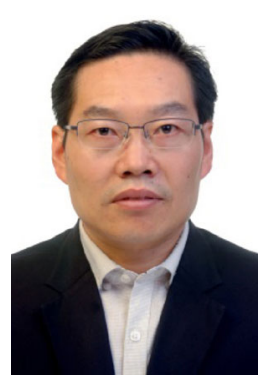

Le GU. He received his M.S and Ph.D degrees in mechanical engineering from Harbin Institute of Technology, Harbin, China. in 1998 and 2003, respectively. He joined the MIIT Key Laboratory of Aerospace the MIIT (Ministry of Industry and Information Technology) Key Laboratory of Aerospace Bearing Technology and Equipment at the same university. His research interests include coating tribology and tribology design in mechanical system.

Bearing Technology and Equipment at Harbin Institute of Technology from 1998. His current position is a professor. His research areas cover the tribology of aerospace bearing, lubrication design and life prediction for fundamental mechanical elements. 